\title{
South China Sea warm pool detected in spring from the Navy's Master Oceanographic Observational Data Set (MOODS)
}

\author{
Peter C. Chu and Hsing-Chia Tseng \\ Department of Oceanography, Naval Postgraduate School, Monterey, \\ California \\ C. P. Chang and J. M. Chen \\ Department of Meteorology, Naval Postgraduate School, Monterey, \\ California
}

\begin{abstract}
A South China Sea warm pool with sea surface temperature (SST) higher than $29.5^{\circ} \mathrm{C}$, recently reported by Chu and Chang [1995a, b] and Chu et al. [1997], appears in the central South China Sea (west of the Luzon Island) in borea] spring, strengthens until the onset of the summer monsoon (mid-May), and then weakens and disappears at the end of May. The transient features and interannual variabilities of the warm pool have not yet been studied. Here we use a subset of the U.S. Navy's Master Oceanographic Observation Data Set (MOODS) to investigate the surface thermal features. First, we employed an optimal interpolation scheme to build up a 10-day interval synoptic data set for December 1963 to November 1984 on a $0.5^{\circ} \times 1^{\circ}$ grids (finer resolution in zonal direction) from the MOODS SST data. An ensemble mean SST field $(\overline{\bar{T}})$ was established with a rather weak horizontal gradient $\left(28.5^{\circ} \mathrm{C}\right.$ near the Palawan Island to $26^{\circ} \mathrm{C}$ near the southeast China coast). Second, we performed a composite analysis to obtain the averaged SST anomaly field $\tilde{T}$ deviating from the ensemble mean for the winter and spring seasons (DecemberMay). During December-March, $\widetilde{T}$ is negative almost everywhere throughout the whole South China Sea. In early April, positive $\widetilde{T}$ with closed isoline (warm pool) was evident west of Luzon Island. In May, the central SCS warm anomaly becomes stronger. On May $11-20$, the central SCS warm pool $\left(114^{\circ}-119^{\circ} \mathrm{E}, 14^{\circ}-19^{\circ} \mathrm{N}\right)$ has $\widetilde{T}>1.8^{\circ} \mathrm{C}$. The size of the warm pool is around $200,000 \mathrm{~km}^{2}$. Third, we performed an empirical orthogonal function (EOF) analysis on the residue data $(\widehat{T})$, deviating from $\overline{\bar{T}}+\widetilde{T}$, for the winter and spring seasons, in order to obtain transient and interannual variations of the SST fields. EOF1 accounts for $35.5 \%$ of the variance and resembles the ensemble mean pattern of nearly parallel contours with a maximum value in the southeast and a minimum value in the northwest. EOF 2 accounts for $21.4 \%$ of the variance and is characterized by a warm/cool pool $\left(116^{\circ}-118^{\circ} \mathrm{E}, 16^{\circ}-18^{\circ} \mathrm{N}\right)$ west of the Luzon Island. The corresponding principal component $\left(P C_{2}\right)$ has strong interannual variability with a maximum value of 10 on February 11-20, 1965 and a minimum of -12 on March 21-31, 1964. This indicates the appearance of either a warm pool with a maximum strength of $1.2^{\circ} \mathrm{C}$ or a cool pool with a maximum strength of $-1^{\circ} \mathrm{C}$. Combination of $\widetilde{T}$ and $P C_{2} \times \mathrm{EOF} 2$ leads to an occurrence of a central SCS warm pool from April to May with a warm anomaly varying between $0.8^{\circ}$ and $3^{\circ} \mathrm{C}$.
\end{abstract}

\section{Introduction}

The South China Sea (SCS) has a bottom topography (Figure 1) that makes it a unique semi-enclosed ocean basin that is overlaid by a pronounced monsoon sur-

This paper is not subject to U.S. copyright. Published in 1997 by the American Geophysical Union.

Paper number 97JC00628.

0148-0227/97/97JC-00628\$09.00 face wind. Extended continental shelves (less than 100 $m$ deep) are found on the western and southern parts, while steep slopes with almost no shelves are found in the eastern part of SCS. The deepest water is confined to a bowl-type trench. The maximum depth is around $4700 \mathrm{~m}$.

On the basis of limited data sets, both cool and warm pools exist in SCS. Dale [1959] reported a cool pool off the central Vietnamese coast in summer. Nitain [1970] 


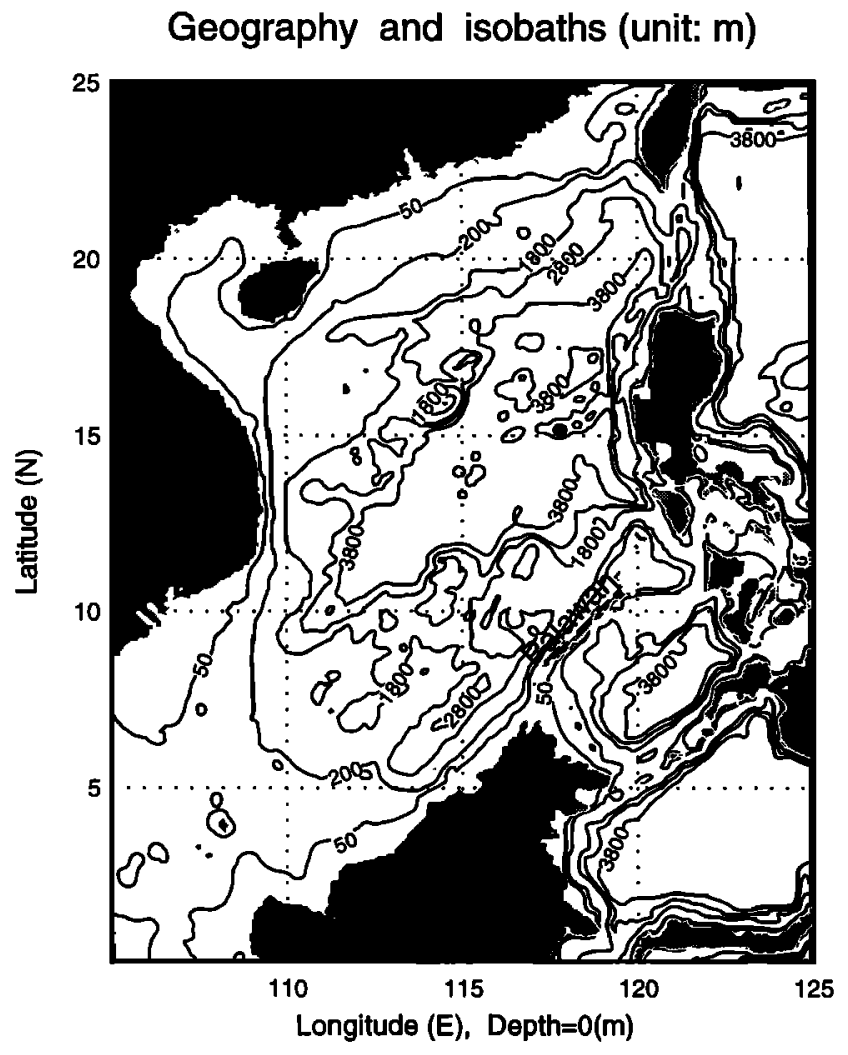

Figure 1. Geography and isobaths showing the bottom topography of the South China Sea.

found a cool pool located to the northwest of Luzon. Reports from the South China Sea Institute of Oceanology (SCSIO) [SCSIO, 1985] indicate that in the central South China Sea, a warm pool appears in both summer and winter but closer to Vietnam in summer at the surface. Recently, a warm pool was reported in the central SCS during the late spring season [Chu and Chang, 1995a,b; Chu et al., 1997; Tseng, 1995] and a cool pool was detected in the central SCS during December 29, 1993 to January 5, 1994, from the analysis of TOPEX/POSEIDON data [Soong, et al., 1995].

An international South China Sea Monsoon Experiment (SCSMEX) was recently initiated. Two of the major objectives are to identify the influence of heating contrasts between the SCS and surrounding regions and the role of early monsoon (April-May) convection and multiscale processes in the SCS in the abrupt transition and subsequent evolution of the East Asian monsoon [SCSMEX Science Plan, 1995]. As a part of the SCSMEX effort, our interest was concentrated on the spatial and temporal variabilities of the SCS thermal fields from December to May.

\section{Master Oceanographic Observational Data Set (MOODS)}

We use the extensive U.S. Navy's Master Observational Oceanographic Data Set (MOODS) for the study. The MOODS is a compilation of ocean data observed worldwide consisting of (1) temperature-only profiles,
(2) both temperature and salinity profiles, (3) soundspeed profiles, and (4) surface temperature (drifting buoy). These measurements are, in general, irregular in time and space. Due to the shear size (more than six million profiles total for the global ocean) and constant influx of data to the Naval Oceanographic Office (NAVOCEANO) from various sources, quality control is very important. The primary editing procedure included removal of profiles with obviously erroneous location, profiles with large spikes (temperature higher than $35^{\circ} \mathrm{C}$ and lower than $-2^{\circ}$ do not match the characteristics of surrounding profiles, such as profiles showing increase of temperature with depth. After quality control, the historical MOODS data (1900-1995) consisted of 189,059 profiles for the whole SCS $\left(5^{\circ} \mathrm{S}-25^{\circ} \mathrm{N}, 105^{\circ}\right.$ $120^{\circ} \mathrm{E}$ ). Our study domain is a subarea of SCS covering $9^{\circ}$ to $25^{\circ} \mathrm{N}$ and $109^{\circ}$ to $120^{\circ} \mathrm{E}$, and our investigation period is December 1963 to November 1984. The total number of profiles of this subset is 70,546. For convenience, we group the previous year's December data with the current year's January-November data; for example, the 1964 data set includes the data of December 1963 to November 1964.

The temporal and spatial distribution of MOODS data is irregular. Certain periods and areas are very well sampled, while others lack enough observations to gain any meaningful insights. There exist some 10 to 20 day gaps with no observations in the whole SCS. Figure 2 shows the sparsity of profiles in the southeast portion of the study domain (from Liyue Bank, Zhenghe Reef to Yingqing Reef) and in the coastal region of China continent. Figure 3 indicates a heavily sampled period during the Vietnamese War (1965-1969). The maximum number of observations is in 1965 (around 7200 profiles). The minimum number of observations is in 1984 (near 980 profiles). Furthermore, vertical resolution and data quality are also highly variable depending much on instrument type and sampling expertise. Temporal and spatial irregularities along with the data resolution and quality problems must be carefully weighed in order to avoid mathematically induced variability.

\section{Establishment of Gridded Data}

We use $1^{\circ} \times 1^{\circ}$ monthly sea surface temperature (SST) climatology [Levitus, 1982] as the mean field and an optimum interpolation scheme to obtain gridded data from the MOODS data. For 1964-1984, the SST perturbations $T_{1}^{\prime}, T_{2}^{\prime}, \ldots, T_{N}^{\prime}$ for SST observations were obtained by subtracting the climatological value at the closest grid from the observation. Optimum interpolation assigns a weight to each observation that accounts for variation in spatial sampling. The interpolated temperature anomaly at the grid point, $T_{G}^{\prime}$, is a linear combination of the observed anomalies, $T_{1}^{\prime}, T_{2}^{\prime}, \ldots, T_{N}^{\prime}$ with weights $\alpha_{1}, \alpha_{2}, \ldots, \alpha_{N}$ :

$$
T_{G}^{\prime}=\sum_{i=1}^{N} \alpha_{i} T_{i}^{\prime}
$$




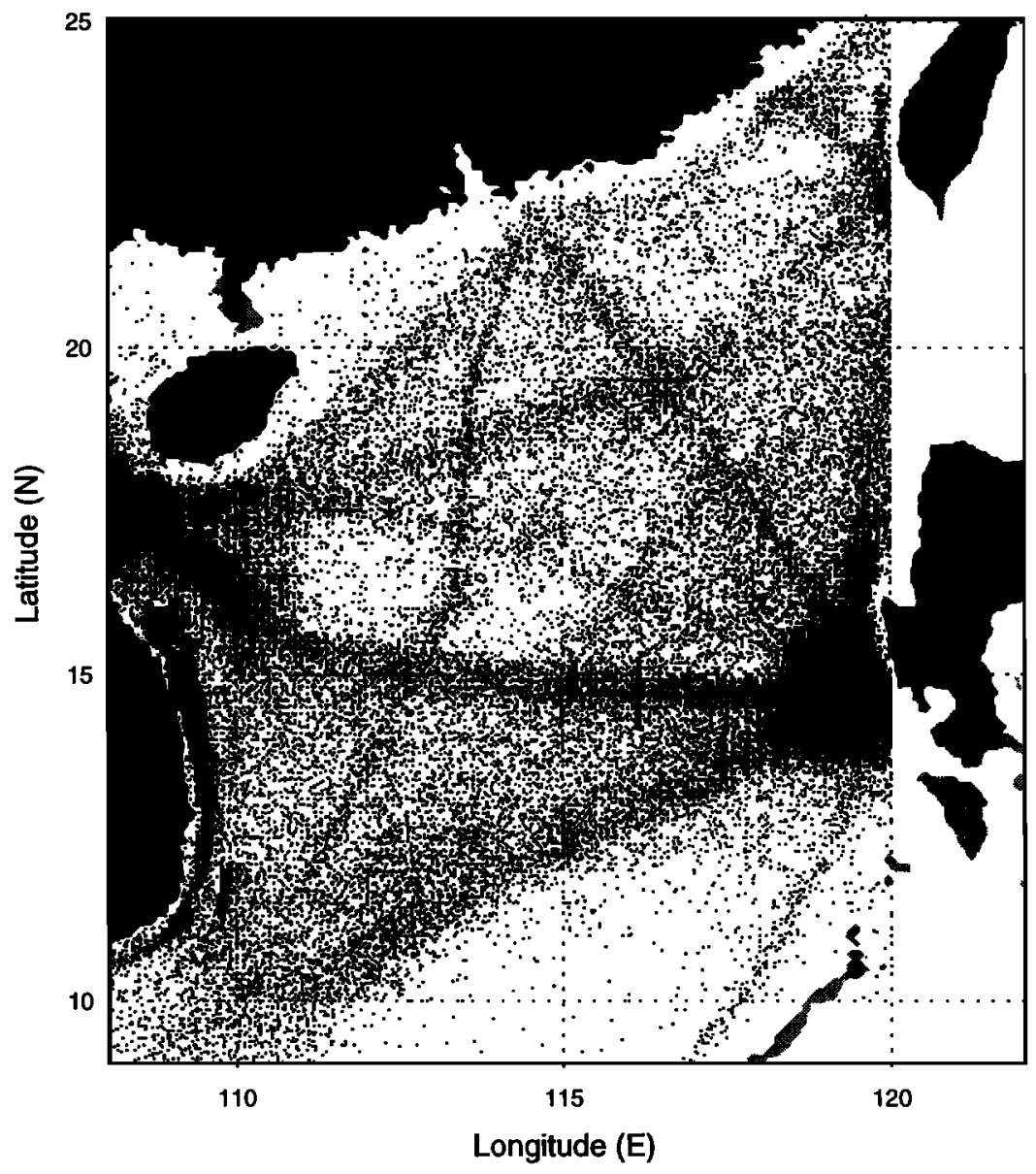

Figure 2. Spatial distribution of MOODS stations during 1964-1984 for this study.

The values of the weights, $\alpha_{i}(i=1,2, \ldots, N)$, are found by minimizing, in a least square sense, the difference between the interpolated value at the grid point and the true value there and are obtained from solving the algebraic equations [Gandin, 1965]:

$$
\sum_{j=1}^{N} \alpha_{j} \mu_{\imath \jmath}+\lambda^{-2} \alpha_{\imath}=\mu_{G i}, i=1,2, \ldots, N .
$$

Here $\lambda$ is the signal-to-noise ratio, $\mu_{i j}$ is the autocorrelation between locations $i$ and $j$, and $\mu_{G z}$ is the autocorrelation between the grid point and location $i$. The autocorrelation function (ACF) is defined by

$$
\mu=\frac{1}{s^{2}} \int^{R} T^{\prime}\left(r_{0}\right) T^{\prime}\left(r_{0}+r\right) d r_{0}
$$

where $r_{0}$ denotes the independent space vector defining the location of points in a sampling space $R, r$ is the space lag, and $s^{2}$ is the variance. Here $\mu$ is computed by paring the anomalies into bins depending upon their separation in space, $r$. The values of $\mu$ will be obtained from calculating the correlation coefficient for all the anomaly pairs in each bin and represented by a Gaussian model for the combination of different lags

$$
\eta(m)=\eta(0) \exp \left[-A^{2}(m \Delta r)^{2}\right]
$$

where $\eta(m)$ denotes the ACF value in the bin with the horizontal separation $m \Delta r . \Delta r=10 \mathrm{~km}$ is the increment for the space/time separation. $A^{-1}$ is the horizontal decorrelation scale. Therefore the autocorrelations $\mu_{i j}$ and $\mu_{G i}$ are given by

$$
\mu_{i j}=\eta\left(m_{\imath j}\right), \quad \mu_{G \imath}=\eta\left(m_{G i}\right)
$$

where $m_{i j}$ and $m_{G i}$ represent spatial separations between locations $i$ and $j$ and between location $i$ and grid point, respectively.

We applied this optimal interpolation method to build up a near-10-day interval synoptic data set from December 1963 to November 1984 on a $0.5^{\circ} \times 1^{\circ}$ grid (finer resolution in the zonal direction) from the MOODS temperature data. Our total gridded data set consists of 756 consecutive SST fields. 


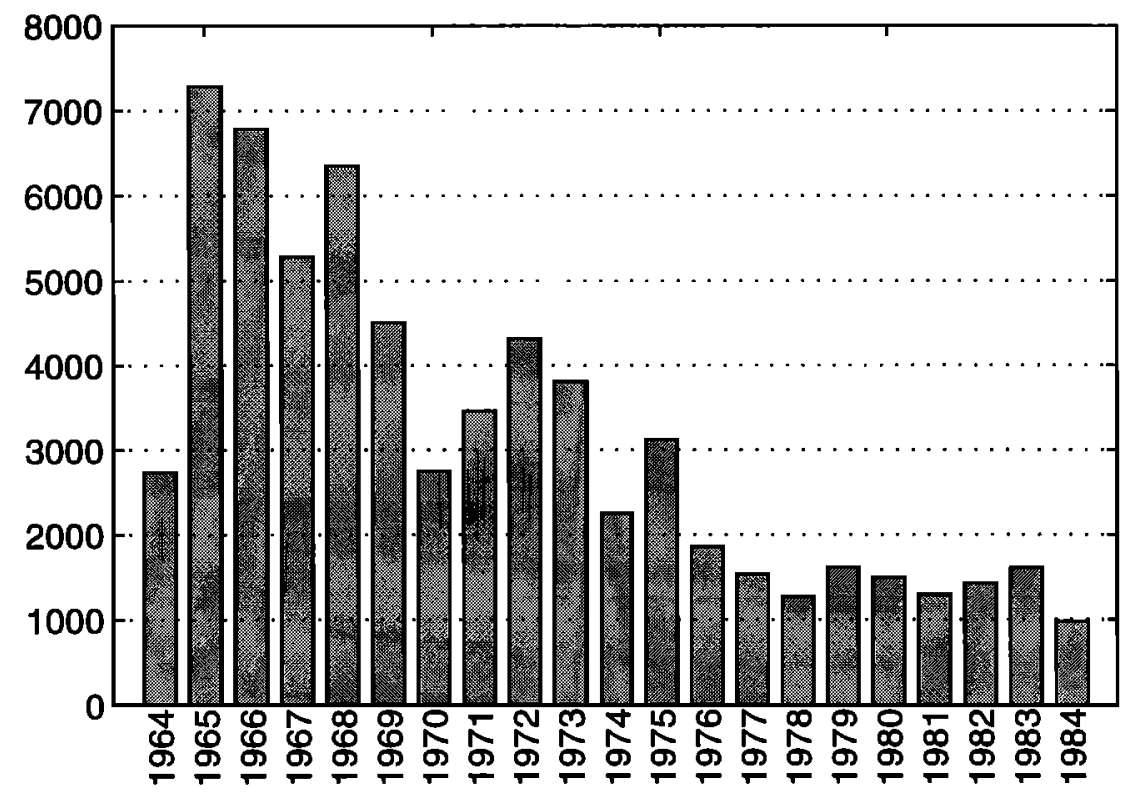

Figure 3. Temporal distribution of MOODS stations during 1964-1984 for this study.

\section{Composite Analysis}

We now examine the data to see if we can obtain a warm pool signal in the mean seasonal (winter to spring) data. After the gridded data set is established, the SST data are represented by $T\left(x_{2}, y_{j}, \tau_{k}, t_{l}\right)$, where $\left(x_{i}, y_{j}\right)$ is the horizontal grids, $\tau_{k}=1964,1965, \ldots$, 1984 is the time sequence in years, and $t_{l}=1,2, \ldots, 36$ is the time sequence within a year in 10-day intervals. The first 10-day interval in the year starts from December; that is, $t_{l}=1$ represents December 1-10 (previous year), $t_{l}=2$ denotes December 11-20 (previous year), $\ldots, t_{l}=4$ refers to January 1-10 (current year), ..., and $t_{l}=36$ indicates November 21-30 (current year). Before investigating the annual variation of SST, we define the following two temporal averages:

$$
\begin{array}{r}
\bar{T}\left(x_{i}, y_{j}, t_{l}\right) \equiv \frac{1}{\Delta \tau} \sum_{k} T\left(x_{i}, y_{j}, \tau_{k}, t_{l}\right) \\
\Delta \tau=21(1984-1964)
\end{array}
$$

which are the annual mean values, and

$$
\overline{\bar{T}}\left(x_{i}, y_{j}\right) \equiv \frac{1}{36} \sum_{l=1}^{36} \bar{T}\left(x_{i}, y_{j}, t_{l}\right)
$$

which are the ensemble mean values. The ensemble mean (1964-1984) SST field over the SCS (Figure 4) shows a pattern of northeast-southwest oriented isotherms with a positive temperature gradient toward southeast near the equator. The ensemble mean has a rather weak horizontal temperature gradient. $\overline{\bar{T}}$ decreases from $28.5^{\circ} \mathrm{C}$ west of Palawan to $26^{\circ} \mathrm{C}$ near the southeast China coast.

The annual mean values deviated from the ensemble mean, $\overline{\bar{T}}\left(x_{i}, y_{j}\right)$,

$$
\widetilde{T}\left(x_{i}, y_{j}, t_{l}\right)=\bar{T}\left(x_{i}, y_{j}, t_{l}\right)-\overline{\bar{T}}\left(x_{i}, y_{j}\right)
$$

lead to the composite features of the 10-day mean SST anomalies. Figures 5 and 6 show $\widetilde{T}\left(x_{i}, y_{j}, t_{l}\right)$, $t_{l}=1,2, \ldots, 18$, since we are only interested in the thermal fields for the first part of the year (December to May),

The 10-day mean SST anomaly $(\widetilde{T})$ has the following features:

1. The first feature is a cooling phase. During December to March, $\widetilde{T}$ is negative almost everywhere

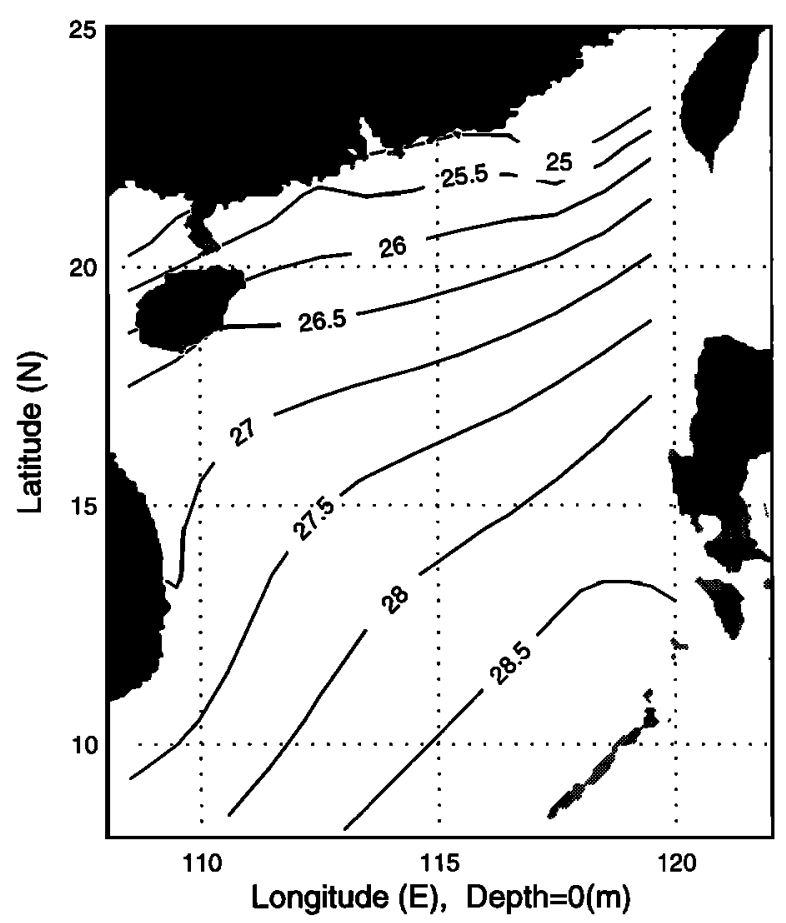

Figure 4. The ensemble mean of the SST field during 1964-1984. 
(a)

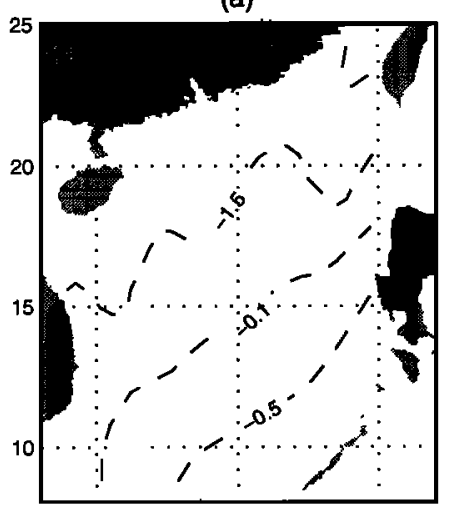

(d)

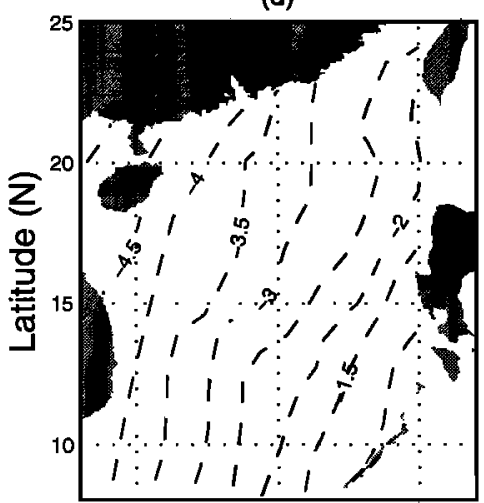

(g)

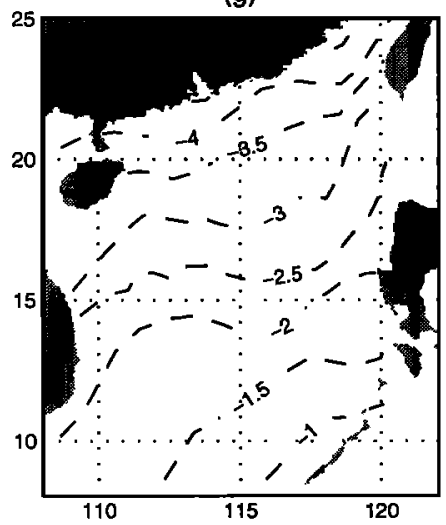

(b)

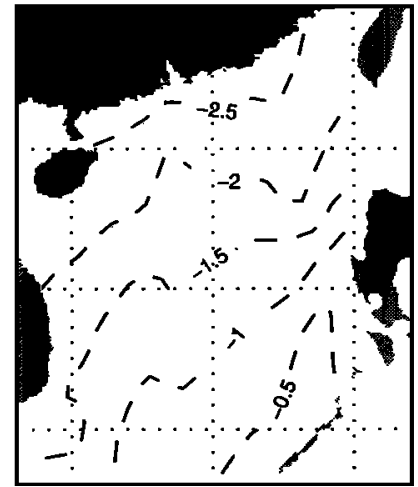

(e)

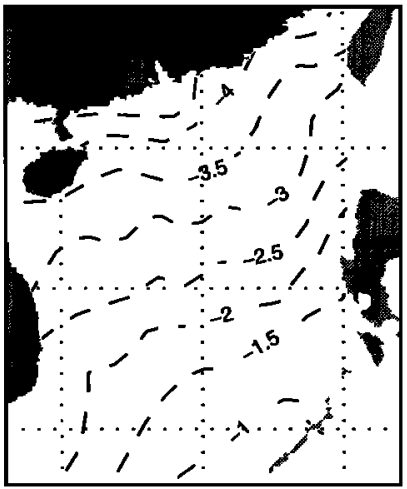

(h)

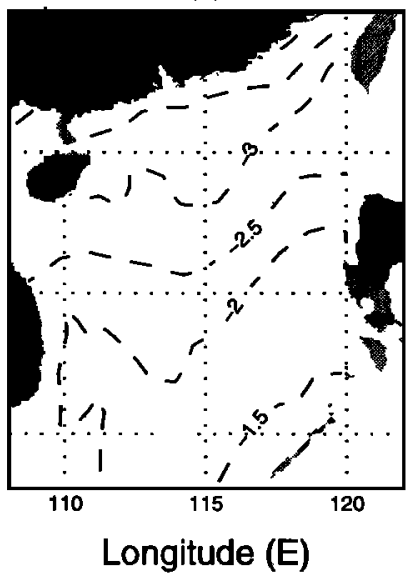

(c)

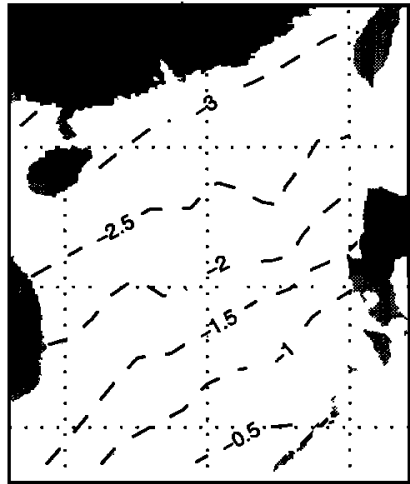

(f)

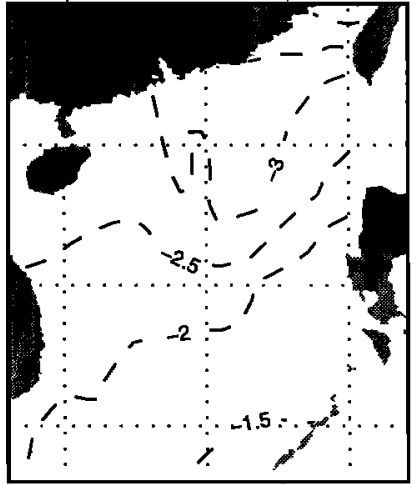

(i)

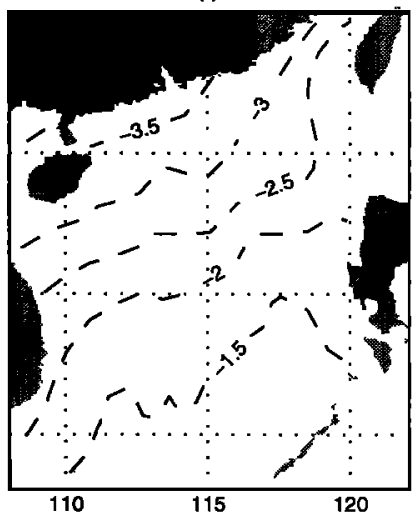

Figure 5. Averaged 10-day SST anomalies relative to the ensemble mean from December to February: (a) December 1-10, (b) December 11-20, (c) December 21-31, (d) January 1-10, (e) January 11-20, (f) January 21-31, (g) February 1-10, (h) February 11-20, (i) February 21-28 (or 29). Solid (dashed) contours denote positive (negative) anomalies.

throughout the whole domain and becomes more negative from the west coast of Palawan to the southeast coast of China. This indicates that the SCS cooling during the winter monsoon season is the weakest in the southeast SCS and the strongest near the Taiwan Strait $\left(\leq-3^{\circ} \mathrm{C}\right)$.

2. The second feature is an early warming phase. In early April, positive $\widetilde{T}$ is evident west of Luzon Island and west of Palawan Island. At the Luzon Strait, $\widetilde{T}$ stays negative until late April (April 21-30). This means that early SCS warming, starting in the southeast SCS and advecting to the central SCS, is not forced by the Kurushio intrusion. It also implies that the Kuroshio water entering SCS in April might be cooler than the SCS water (at least at the surface).

3. The third stage is a mature warming phase. In May, the central SCS warm pool becomes stronger than the early warming phase. During May 11-20, the central 
(a)

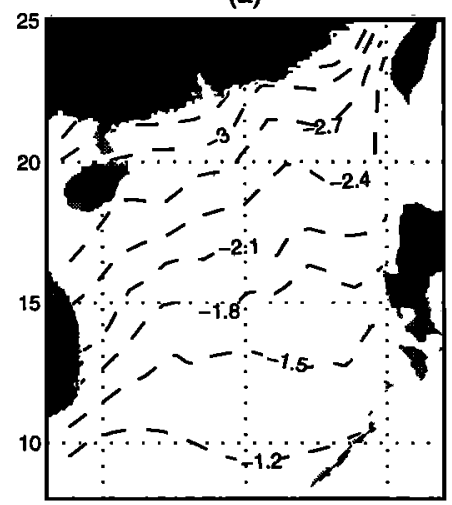

(d)

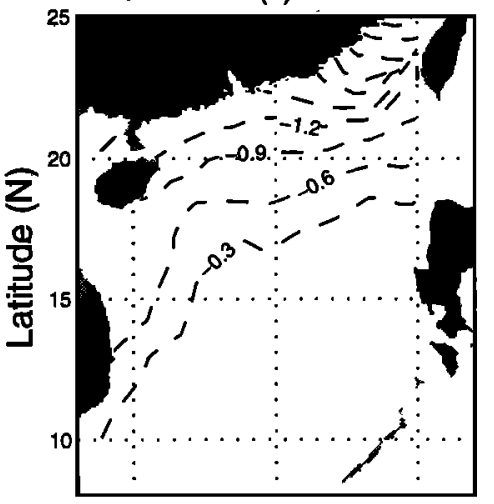

(g)

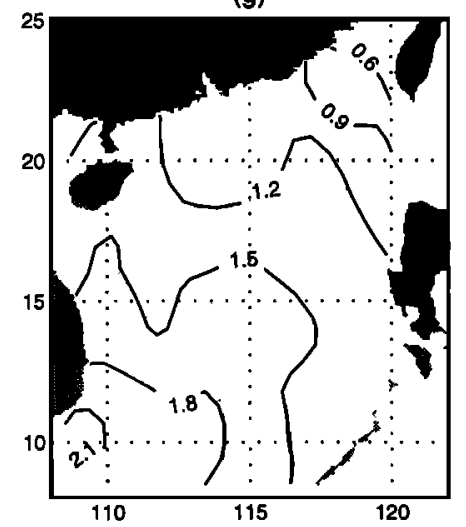

(b)

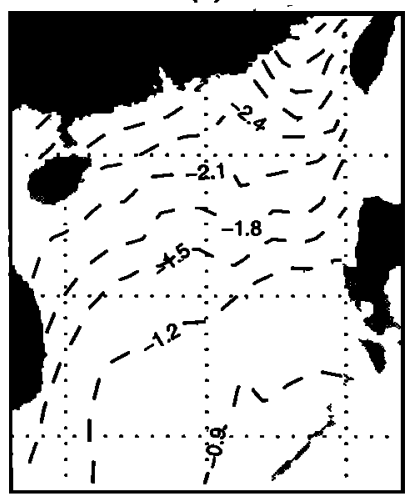

(e)

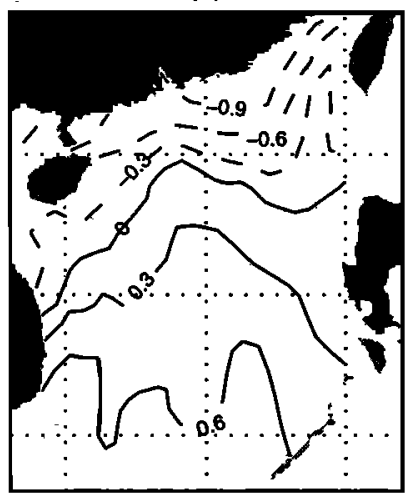

(h)

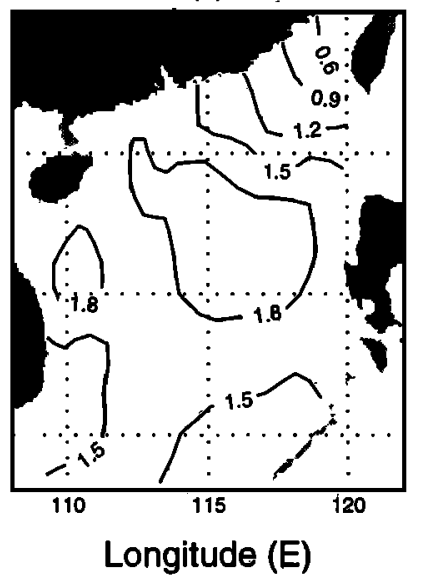

(c)

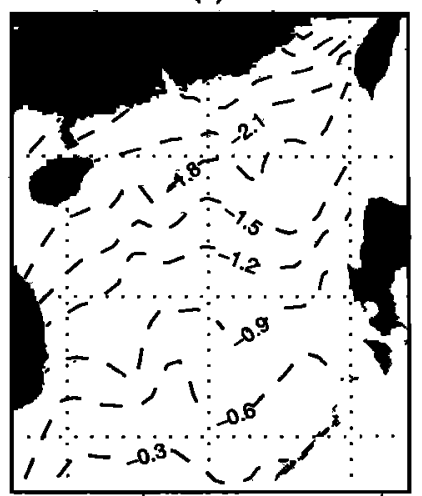

(f)

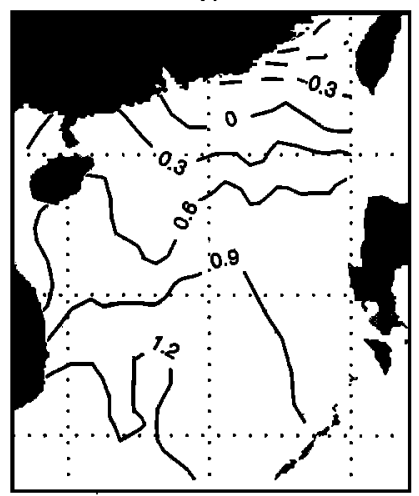

(i)

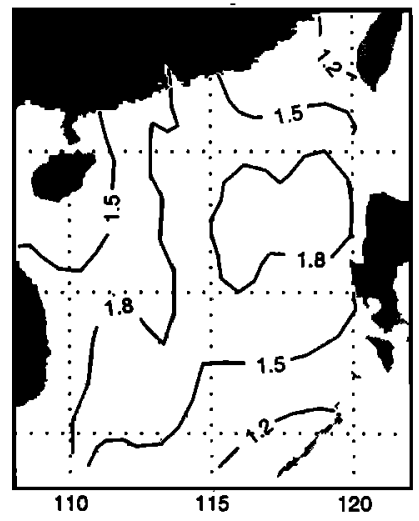

Figure 6. Averaged 10-day SST anomalies relative to the ensemble mean from March to May: (a) March 1-10, (b) March 11-20, (c) March 21-31, (d) Aprịl 1-10, (e) April 11-20, (f) April 21-30, (g) May 1-10, (h) May 11-20, (i) May 21-31. Solid (dashed) contours denote positive (negative) anomalies.

SCS warm pool $\left(114^{\circ}-119^{\circ} \mathrm{E}, 14^{\circ}-19^{\circ} \mathrm{N}\right)$ has $\tilde{T}>1.8^{\circ} \mathrm{C}$ and accounts for the maximum mean warm anomaly. The size of the warm pool is around $200,000 \mathrm{~km}^{2}$.

\section{Empirical Orthogonal Function (EOF) Analysis}

The composite analysis shows the existence of a central SCS warm pool in the 10-day mean SST anomaly data during April to May. What are the transient features of the SCS warm pool? What are the synoptic and interannual variabilities of SCS warm pool? We used empirical orthogonal function (EOF) analysis to investigate these issues.

\subsection{EOFs for the SST Anomalies}

The SST synoptic anomalies obtained by

$$
\widehat{T}\left(x_{i}, y_{j}, \tau_{k}, t_{l}\right)=T\left(x_{i}, y_{j}, \tau_{k}, t_{l}\right)-\bar{T}\left(x_{i}, y_{j}, t_{l}\right)
$$

are re-arranged into a $N \times P$ matrix, $\widehat{T}\left(\mathrm{r}_{n}, \widetilde{t}_{p}\right), n=$ $1,2, \ldots, N$; and $p=1,2, \ldots, P$. Here $P=378$ is the total number of time points used for computing the covariance matrix, i.e., 21 years of every 10 -day measure- 
ments from December to May; $N=255$ corresponds to the number of grids $(i=1,2, . ., 17 ; j=1,2, \ldots 15)$. Empirical orthogonal function analysis [Lorenz, 1956], widely used in oceanographic and meteorological research [e.g., Weare et al., 1976] (see review by Richman, [1986]) is the same as principal component (PC) analysis [Hotelling, 1933] in the statistics community. $\mathrm{PCs}$ are the amplitudes, which are functions of time, of their corresponding EOFs. These EOFs can be found by calculating the unitary eigenvectors of the covariance matrix associated with the sample data field. EOF analysis separates the data sets into eigenmodes. Generally speaking, each mode has an associated variance, nondimensional spatial pattern, and dimensional time series. One nice feature of the EOF analysis is that it does not require the data to be continuous in time. We can analyze the data from December to May to investigate the variability during that period. Therefore we have 378 time points in the EOF analysis. From this data matrix a 255-square spatial covariance matrix is calculated by

$$
\begin{array}{r}
R=\left[\begin{array}{cccc}
R_{11} & R_{12} & \ldots & R_{1 N} \\
R_{21} & R_{22} & \ldots & R_{2 N} \\
& \ldots \ldots & & \\
R_{N 1} & R_{N 2} & \ldots & R_{N N}
\end{array}\right], \\
R_{n m}=\sqrt{\frac{1}{P} \sum_{p} \hat{T}\left(\mathbf{r}_{n}, \tilde{t_{p}}\right) \hat{T}\left(\mathbf{r}_{m}, \tilde{t}_{p}\right)}, \\
N=255, P=378
\end{array}
$$

where $n$ and $m(1,2, \ldots, N)$ denote the grid locations. The diagonal elements of the covariance matrix $R_{n n}(n=$ $1,2, \ldots, N)$ are the variance at location $\mathbf{r}_{n}$. The offdiagonal elements are the covariance with spatial lag equal to the difference between the row and column indices. This symmetric matrix has its $N$ real eigenvalues $\lambda_{\alpha}$ and eigenvectors $\phi_{\alpha}\left(\mathbf{r}_{j}\right)$, such that

$$
\sum_{j=1}^{N} R_{i j} \phi_{\alpha}\left(\mathbf{r}_{j}\right)=\lambda_{\alpha} \phi_{\alpha}\left(\mathbf{r}_{i}\right), \quad i=1,2, \ldots, N
$$

The eigenvectors $\phi_{1}, \phi_{2}, \ldots, \phi_{N}$ are called empirical orthogonal functions. Each $\phi_{\alpha}$ is a 255 -point $(17 \times 15$ grid in this study) distribution of SST anomaly pattern. The eigenvalues, $\lambda_{\alpha}(\alpha=1,2, \ldots, N)$, are all positive, and the summation of them, $\sum \lambda_{\alpha}$, equals the total variance. Therefore $\lambda_{\alpha}$ is considered as the portion of total variance "explained" by the EOF $\phi_{\alpha}$. It is convenient to label the eigenfunctions $\phi_{\alpha}$ so that the eigenvalues are in descending order, i.e.,

$$
\lambda_{1}>\lambda_{2}>\lambda_{3}>\ldots
$$

\subsection{Principal EOF Modes}

Intraseasonal and interannual anomalies can be quantitatively investigated with the method of EOF analysis and a number of its generalized forms. In order to delineate the major modes of variability in winter and spring seasons (December to May) of 21 years (1964-1984), we perform an EOF analysis using the method outlined in section 5.1 and obtain the first six leading EOFs, which are able to account for almost $81.7 \%$ of the total variance during the seasons (Table 1). When combined, EOF1 and EOF2 explain over half (57\%) of the total variance. Each EOF mode is normalized so that its total spatial variance is equal to unity. So those patterns of the first six EOFs are enough to explain the spatial anomalies of whole SCS. Hence it suffices to focus on the first six EOFs. Their structures are shown in Figure 7.

The EOF1 mode (Figure 7a) has a NE-SW orientation and accounts for up to $35.6 \%$ of the total spatial variance during December to May. This pattern is believed to be related to the ensemble mean pattern. This indicates that such a pattern (NE-SW orientation) repeats in time. To illustrate the possibility of the same pattern occurring in the mean and EOF 1 fields, we assume that a data set contains only one pattern $A$ with the amplitude varying in time. Then the mean field is simply the pattern $A$ with the average amplitude, and the EOF (only one) is also the pattern $A$. By removing the mean from the data field, the average value of the EOF amplitudes now vanishes. The EOF2 mode (Figure $7 \mathrm{~b}$ ) has a closed isoline of -0.1 to the west of Luzon Island $\left(116^{\circ}-118^{\circ} \mathrm{E}, 16^{\circ}-18^{\circ} \mathrm{N}\right)$ and accounts for about $21.4 \%$ of variance. This warm/cool pool is embedded into the warm pool identified by the composite analysis. However, we still cannot identify whether EOF2 represents a warm or cool pool since the values in Figure 7 are normalized. We should consider the product of the EOF values and the corresponding time series of the amplitudes, also called PC components.

\subsection{Temporal Variabilities}

The data matrix, $\widehat{T}\left(x_{i}, y_{j}, \tau_{k}, t_{l}\right)$, is thus written by

$$
\widehat{T}\left(x_{i}, y_{j}, \tau_{k}, t_{l}\right)=\sum_{\alpha} P C_{\alpha}\left(\tilde{t}_{p}\right) \phi_{\alpha}\left(x_{i}, y_{j}\right)
$$

where $P C_{\alpha}\left(\tilde{t}_{p}\right)$ is the principal component with a unit of degree Celsius and a size of $P$, representing the temporal variation of the associated spatial pattern described by EOF $\phi_{\alpha}\left(x_{i}, y_{j}\right)$. The time series is analogous to a projection of SST anomaly through the "filter" of an EOF mode during a time scale.

Table 1. Variances of the First Six Leading EOFs

\begin{tabular}{llr}
\hline EOF & Variance, \% & \multicolumn{2}{c}{ Cumulative Variance, \% } \\
\hline & & \\
1 & 35.6 & 35.6 \\
2 & 21.4 & 57.0 \\
3 & 12.4 & 69.4 \\
4 & 5.3 & 74.7 \\
5 & 4.7 & 79.4 \\
6 & 2.3 & 81.7
\end{tabular}


(a)

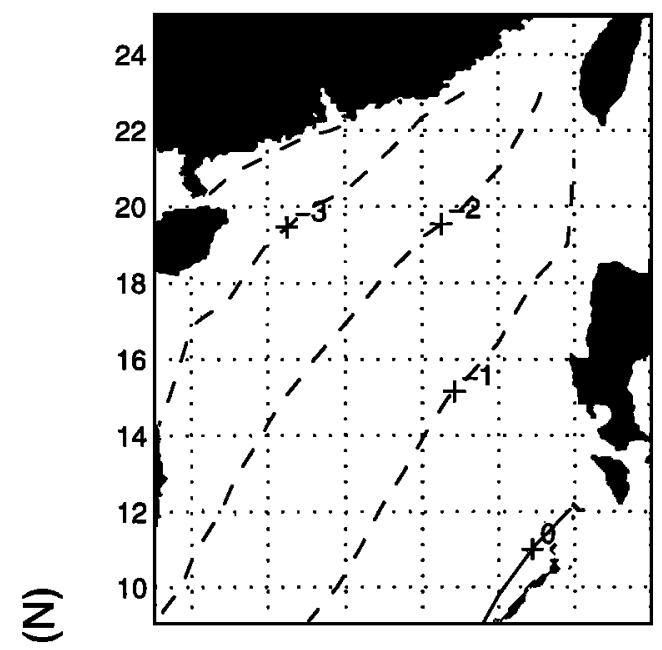

(d)

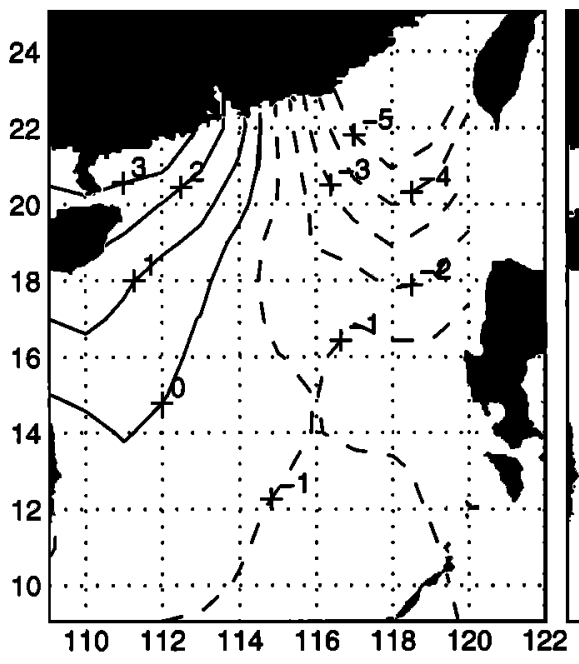

(b)

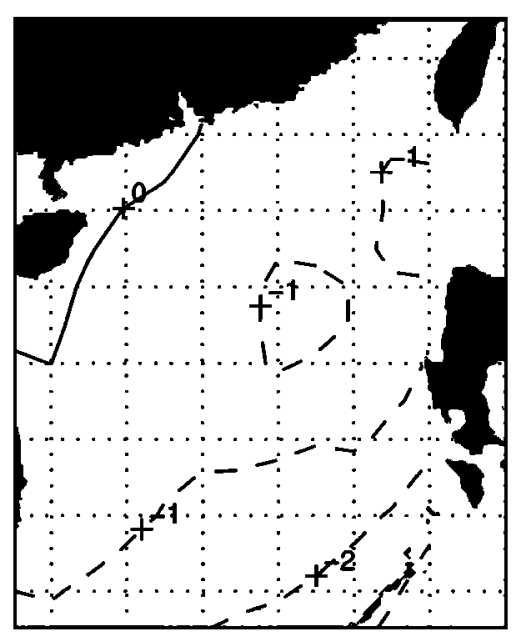

(e)

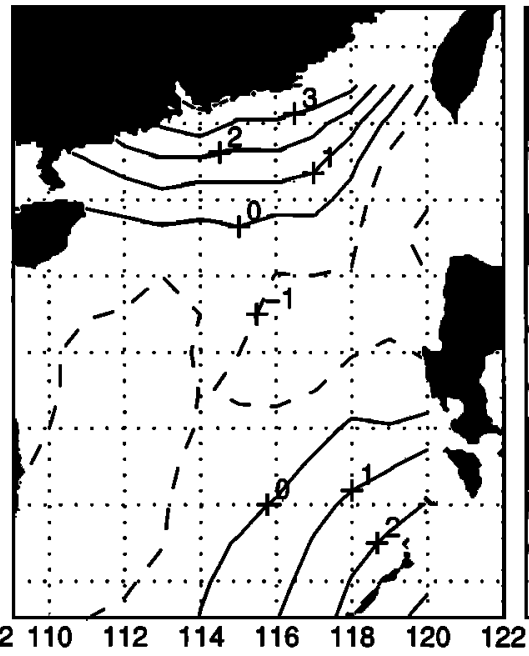

(c)

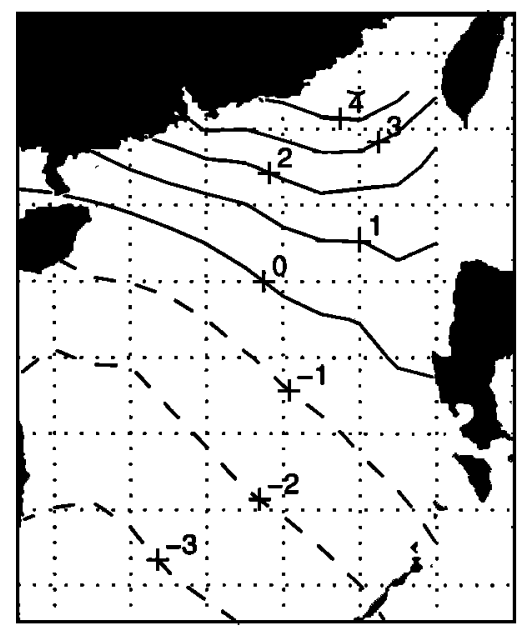

(f)

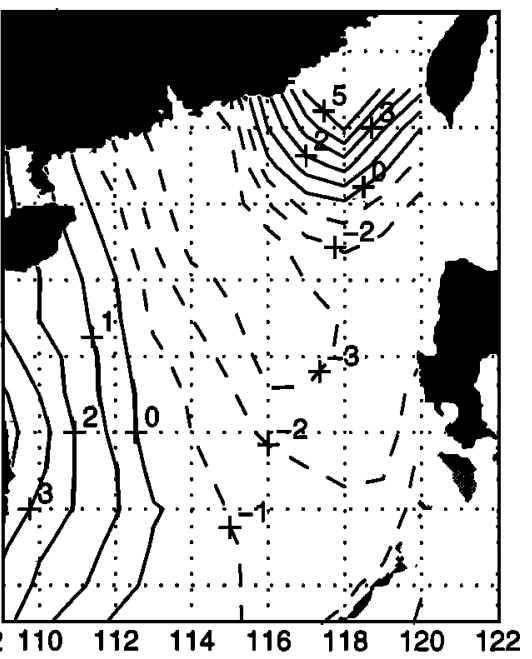

\section{Longitude $(E)$}

Figure 7. First six EOF modes (the values were multiplied by 10) computed from January-May data during 1964-1984: (a) EOF1, (b) EOF2, (c) EOF3, (d) EOF4, (e) EOF5, and (f) EOF6. Solid (dashed) contours denote positive (negative) values.

The first principal component, $P C_{1}\left(\widetilde{t}_{p}\right)$, for 1964 1984 is shown in Figure 8. The EOF1 mode $\phi_{1}\left(x_{i}, y_{j}\right)$ is always negative throughout the whole domain (Figure 7a). Therefore $P C_{1}\left(\widetilde{t}_{p}\right)>0$ corresponds to negative SST anomalies, and $P C_{1}\left(\tilde{t}_{p}\right)<0$ corresponds to positive SST anomalies. Taking the year of 1968 as an example, $P C_{1}\left(\widetilde{t}_{p}\right)$ is always positive from early December (1967) to late April (1968), which implies the negative SST anomalies in the whole SCS during this period. Furthermore, the variability of EOF1 (Figure 7a) is small west of Palawan Island and increases northwestward toward the southeast coast of China.

The second principal component, $P C_{2}\left(\widetilde{t}_{p}\right)$, for 19641984 is shown in Figure 9. The EOF2 mode $\phi_{2}\left(x_{i}, y_{j}\right)$ is negative throughout the whole domain and shows a closed isoline of -0.1 to the west of Luzon Island (Figure $7 \mathrm{~b})$. As before, $P C_{2}\left(\widetilde{t}_{p}\right)>0$ corresponds to negative SST anomalies, and $P C_{2}\left(\tilde{t}_{p}\right)<0$ corresponds to positive SST anomalies. Taking the year of 1964 as an example, $P C_{2}\left(\widetilde{t}_{p}\right)$ is almost always negative from December 1963 to early May and reaches a minimum value of -12 on March 21-31, which implies positive SST anomalies over the whole SCS with a warm pool component to the west of Luzon Island during 1964 winter and spring seasons. The maximum SST anomaly of the warm pool in 1964 is around $1.2^{\circ} \mathrm{C}\left[-0.1 \times\left(-12^{\circ}\right)\right]$. On the other hand, taking the year of 1965 as another example, $P C_{2}\left(\widetilde{t}_{p}\right)$ has a maximum value of 10 (mid February), which implies negative SST anomalies in the whole domain and a cool pool component to the west of Lu- 

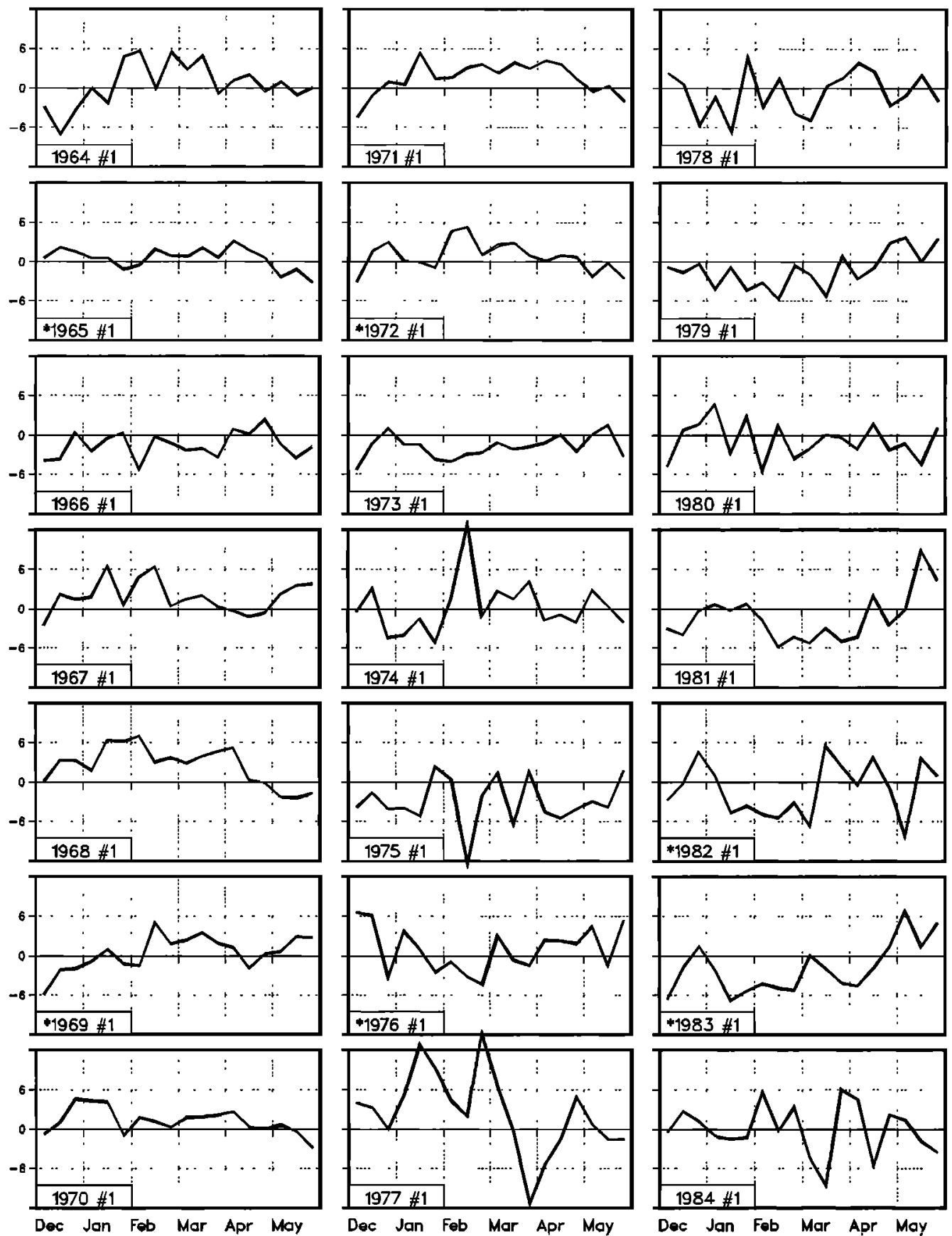

Figure 8. Time series of $P C_{1}$ (December to May) for 1964-1984. The unit is degrees Celsius.

zon Island with a magnitude of $-1^{\circ} \mathrm{C}\left(-0.1 \times 10^{\circ} \mathrm{C}\right)$ on February $11-20,1965$. This indicates the appearance of either a warm pool with a maximum strength of $1.2^{\circ} \mathrm{C}$ or a cool pool with a maximum strength of $-1^{\circ} \mathrm{C}$.

Combination of $\widetilde{T}$ and $P_{C_{2}} \times \mathrm{EOF} 2$ leads to an occurrence of a central SCS warm pool from April to May with a warm anomaly varying between $0.8^{\circ}$ and $3^{\circ} \mathrm{C}$.

\section{A Possible Combined Wind-Topography Effect}

The bowl-type bottom topography shown in Figure 1 provides a favorable condition for the central SCS warm pool formation in spring. When the surface wind stress curl over the central SCS is anticyclonic, Ekman downwelling will occur in the central part of the bowl and upwelling will occur near the boundary of the bowl through mass balance. The downwelling prevents the deep cold water from advecting upward, and the upwelling helps the deep cold water advecting upward. This makes the central part of the bowl warm and the side part of the bowl cool and leads to the generation of the central SCS warm pool.

From late winter to early spring, a surface anticyclone usually appears over the central SCS [Cheang, 1987]. This anticyclone generates downwelling in the central 

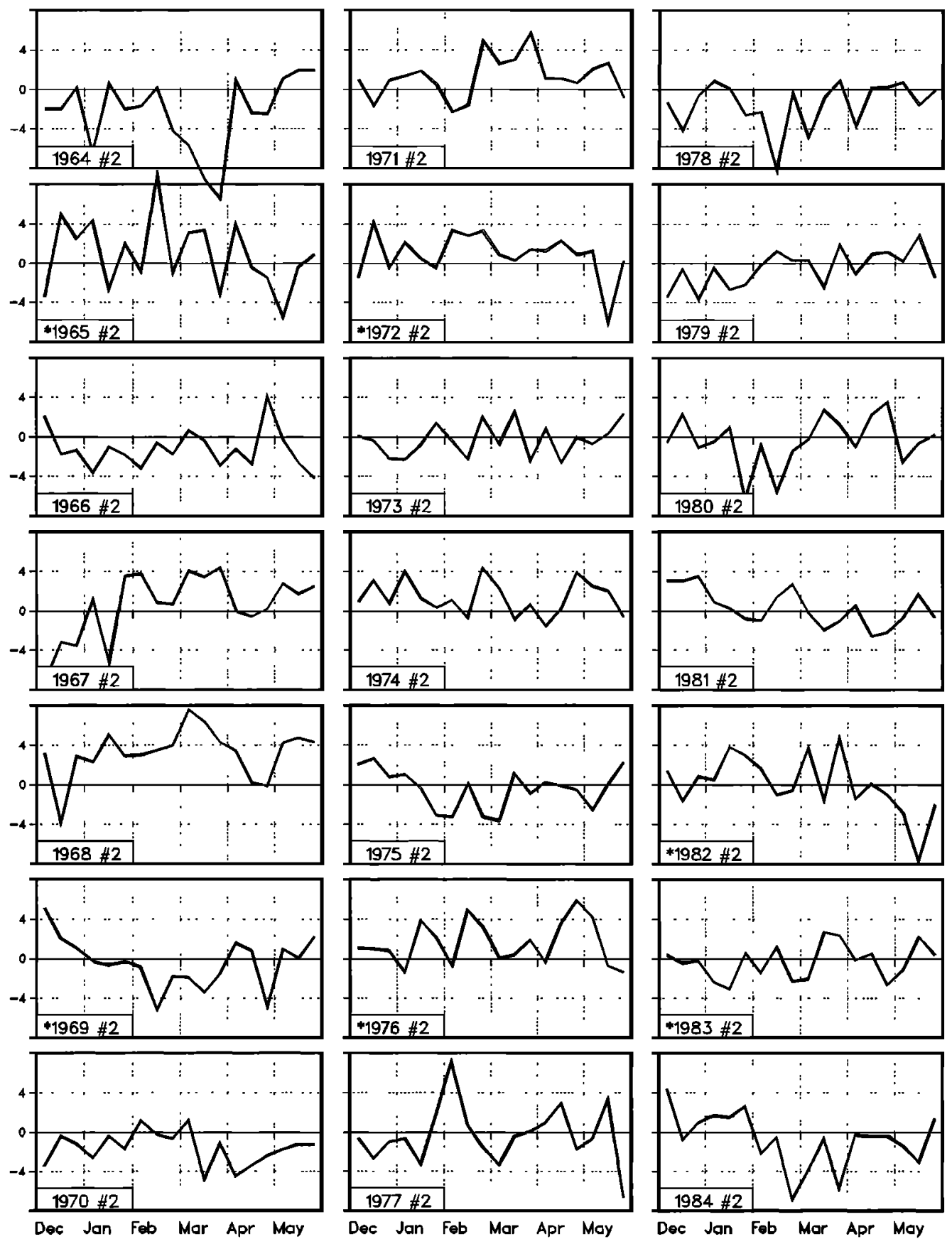

Figure 9. Time series of $P C_{2}$ (December to May) for 1964-1984. The unit is degrees Celsius.

SCS and in turn prevents the cold deep water from being advected to the surface. As spring starts the cold northeast (winter) monsoon diminishes and the sky over the SCS also enters a more clear period with less cloud cover and rainfall and rapidly increasing solar radiative warming at the sea surface. This warm pool, with a temperature (between $0.8^{\circ}$ and $3^{\circ} \mathrm{C}$ ) higher than the surroundings in a generally warm SCS, may lower the atmospheric surface pressure and promote the onset of the southwest (summer) monsoon. The appearance of a cyclonic circulation with the lower pressure after the summer monsoon onset may generate Ekman upwelling in the central SCS, bringing the deep cold water into the surface mixed layer. This process may then destroy the central SCS warm pool.

\section{Conclusions}

Our study shows the existence of a central SCS warm pool during winter and spring seasons from analysis of the Navy's Master Observational Oceanographic Data Set (MOODS). Optimal interpolation, composite analysis, and EOF analysis were used. We obtained the following results:

1. The ensemble mean SST field $(\overline{\bar{T}})$ was established with a rather weak horizontal gradient $\left(28.5^{\circ} \mathrm{C}\right.$ west 
of Palawan Island to $26^{\circ} \mathrm{C}$ near the southeast China Coast).

2. The composite analysis indicates the following features of the averaged SST anomaly fields $\tilde{T}$ relative to the ensemble mean in the winter and spring seasons (December-May). During December to March, $\widetilde{T}$ is negative almost everywhere throughout the whole domain. In early April, positive $\widetilde{T}$ with closed isoline (warm pool) is found west of Luzon Island. The size of the pool is around $200,000 \mathrm{~km}^{2}$. In May, the central SCS warm anomaly becomes significant. On May 11-20, the central SCS warm pool has $\widetilde{T}>1.8^{\circ} \mathrm{C}$.

3. EOF analysis was applied to the residual SST data $\widehat{T}$ (deviated from $\overline{\bar{T}}+\widetilde{T}$ ) to investigate the transient and interannual SST variabilities. EOF1 accounts for $35.5 \%$ of the variance and resembles the ensemble mean pattern of nearly parallel contours with a maximum value in the southeast and a minimum value in the northwest. EOF2 accounts for $21.4 \%$ of the variance and is characterized by a warm/cool pool (embedded into the warm pool identified by the composite analysis) to west of Luzon Island. The corresponding principal component $\left(\mathrm{PC}_{2}\right)$ has strong interannual variability with a maximum value of 10 on February 11-20, 1965 and a minimum of -12 on March 21-31, 1964. This leads to the appearance of either a warm pool with a maximum strength of $1.2^{\circ} \mathrm{C}$ or a cool pool with a maximum strength of $-1^{\circ} \mathrm{C}$. In other words, $P C_{2} \times \mathrm{EOF} 2$ is bounded between $-1^{\circ}$ and $1.2^{\circ} \mathrm{C}$.

4. Combination of $\widetilde{T}$ and $P C_{2} \times$ EOF2 leads to an occurrence of a central SCS warm pool from April to May with a warm anomaly varying between $0.8^{\circ}$ and $3^{\circ} \mathrm{C}$.

5. A combined wind-topography effect is proposed to explain the formation and destruction of the central SCS warm pool. On the other hand, the appearance and disappearance of the central SCS warm pool will affect the atmospheric circulation. Thus the central SCS warm pool might be an important component for the SCS coupled air-ocean system.

Acknowledgments. The authors are grateful to Chenwu Fan, Yuchun Chen, Laura Ehret, and Bao-Fong Jeng for programming assistance. This work was funded by the Naval Oceanographic Office, the Office of Naval Research NOMP Program, and the Naval Postgraduate School.

\section{References}

Cheang, B.K., Short- and long-range monsoon prediction in southeast Asia, in Monsoon, edited by J.S. Fein and P.L. Stephens, pp. 579-606, John Wiley, New York, 1987.

Chu, P.C., and C.P. Chang, A case study of the South China Sea warm pool, paper presented at the Interna- tional CLIVAR-GOALS Workshop on Asian-Australian Monsoon Oceanography and Meteorology, UCAR Joint International Climate Projects/Planning Office, Melbourne, Victoria, Australia, April 10-12, 1995a.

Chu, P.C., and C.P. Chang, South China Sea warm pool and monsoon development, paper presented at the $I n$ ternational South China Sea Monsoon Experiment ( $S C$ $S M E X)$ Scientific Workshop, Chinese National Meteorological Administration, Beijing, China, June 5-7, 1995b.

Chu, P.C., S.H. Lu, and Y.C. Chen, Temporal and spatial variabilities of the South China Sea surface temperature anomaly, J. Geophys. Res., in press, 1997.

Dale, W.L., Winds and drift currents in the South China Sea, Malay. J. Trop. Geogr., 8, 1-31, 1959.

Gandin, L.S., Objective Analysis of Meteorological Fields, 242 pp. Isr. Program for Sci. Transl., Jerusalem, 1965.

Hotelling, H., Analysis of a complex of statistical variables into principal components, J. Educ. Psychol., 24, 417441, 498-520, 1933.

Levitus, S., Climatological atlas of the world ocean, NOAA Prof. Pap., 13, U. S. Gov. Print. Off., Washington, D.C., 1982.

Lorenz, E.N., Empirical orthogonal functions and statistical weather prediction, Sci. Rep. 1, 49 pp. Stat. Forecasting Proj., Dep. of Meteorol., Mass. Inst. of Technol., Cambridge, 1956

Nitain, H., Oceanographic conditions in the sea east of Philippines and Luzon Strait in summer of 1965 and 1966, in: The Kuroshio-A Symposium on Japan Current edited by J.D. Marr, pp. 213-232, East-West Press, Honolulu, Hawaii, 1970 .

Richman, M.B., Rotation of principal components, J. Climatol., 6, 193-235, 1986.

Soong, Y.S., J.H. Hu, C.R. Ho, and P.P. Niiler, Cold-core eddy detected in South China Sea. EOS Trans. $A G U$, 345-347, 1995.

South China Sea Institute of Oceanology, Academia Sinica, Integrated Investigation Report on Sea Area of the South Chına Sea (II), pp. 183-231, Science, Beijing, 1985.

South China Sea Monsoon Experiment Science Plan Working Group, The South China Sea Monsoon Experiment Science Plan, 65 pp., NASA Goddard Space Flight Center, Greenbelt, Md., 1995.

Tseng, H.C., South China Sea warm-core and cool-core eddies detected from the Navy's Master Oceanographic Observation Data Set (MOODS), M.S. thesis, U.S. Nav. Postgrad. School, Monterey, Calif., 1995.

Weare, B.C., A.R. Navato, and R.E. Newell, Empirical orthogonal analysis of Pacific sea surface temperature, $J$. Phys. Oceanogr., 6, 671-678, 1976.

P. C. Chu and H.-C. Tseng, Department of Oceanography, Naval Postgraduate School, Monterey, Californa. (e-mail: chu@nps.navy.mil)

C.P. Chang and J.M. Chen, Department of Meteorology, Naval Postgraduate School, Monterey, California. (e-mail: chu@nps.navy.mil)

(Received November 7, 1995; revised December 3, 1996; accepted February 10, 1997.) 